\title{
IN VITRO ANTIBACTERIAL ACTIVITIES OF DIFFERENT SOLVENT EXTRACTS OF CAJANUS CAJAN L. SEED COAT AND COTYLEDON
}

\author{
PRATIMA H ${ }^{1 *}$, PRATIMA MATHAD ${ }^{2}$ \\ ${ }^{1}$ Department of Postgraduate Studies and Research in Botany, Akkamahadevi Women's University, Vijayapur, Karnataka, India. \\ ${ }^{2}$ Department of Postgraduate Studies and Research in Botany, Gulbarga University, Kalaburgi, Karnataka, India. \\ Email: pratimakalsanki@gmail.com
}

Received: 10 November 2017, Revised and Accepted: 07 February 2018

ABSTRACT

Objectives: The present study was conducted to assess the antibacterial activity of seed coat and cotyledon of Cajanus cajan with various solvents such as petroleum ether, chloroform, ethanol, and aqueous.

Methods: The crude extracts were obtained using Soxhlet successive extraction method. The antibacterial activity of seed coat and cotyledon extracts at different concentration ( 50 and $100 \mathrm{mg} / \mathrm{mL}$ ) was evaluated against certain pathogenic Gram-positive bacteria of Bacillus subtilis, Staphylococcus aureus, and Streptococcus pneumoniae and Gram-negative bacteria of Salmonella typhi, Klebsiella pneumoniae, Escherichia coli, and Pseudomonas aeruginosa by agar well diffusion assay.

Results: The results show that the ethanolic extract of seed coat had highest activity against $B$. subtilis $(22.0 \pm 0.13 \mathrm{~mm})$. Whereas, the aqueous extract of cotyledon had highest activity against $S$. aureus $(20.0 \pm 0.02 \mathrm{~mm})$ and $S$. typhi $(20.0 \pm 0.04 \mathrm{~mm})$ at $100 \mathrm{mg} / \mathrm{mL}$. The $S$. pneumoniae and P. aeruginosa were completely resistant to all extracts of seed coat. Similarly, S. pneumoniae, K. pneumoniae, E. coli, and P. aeruginosa were totally resistant to all tested cotyledon extracts. The phytochemical results show the presence of alkaloids, steroids, phenols, flavonoids, tannins, lignins, glycosides, and absence of saponins in seed coat and cotyledon.

Conclusion: This study shows that $C$. cajan seed coat and cotyledon had potential antibacterial activity against B. subtilis, S. aureus, and S. typhi. These extracts may be exploited for the development of antimicrobial and alternative remedies for infections and diseases caused by respective pathogens.

Keywords: Antibacterial activity, Cajanus cajan, Cotyledon, Phytochemicals, Seed coat.

(C) 2018 The Authors. Published by Innovare Academic Sciences Pvt Ltd. This is an open access article under the CC BY license (http://creativecommons. org/licenses/by/4. 0/) DOI: http://dx.doi.org/10.22159/ajpcr.2018.v11i5.23610

\section{INTRODUCTION}

The medicinal value of plants lies in some chemical substances that produce a definite physiological action on the human body. The secondary metabolites of plants such as alkaloids, flavonoids, tannins, and phenolic compounds are considered as valuable phytochemicals found to be used as an intermediate for the production of new drugs [1]. The study of antibacterial activity is more important in the current years due to the development of antimicrobial drug resistance and often the occurrence of undesirable side effects of some antibiotics [2]. Plants are safer alternative sources of antimicrobials $[3,4]$.

The most commonly consumed legume in India is Cajanus cajan (L.) Millsp (Pigeonpea) and is also the fifth most important pulse in the world. The $C$. cajan being a forage crop has been utilized as a remedy for various ailments. Studies have proved that the $C$. cajan seeds, when added to coffee alleviates headache and vertigo [5]. There are reports on isolation of isoflavones, namely, daidzein (4, 7-dihydroxy-isoflavone) and formononetin (7-hydroxy- 40-methoxy isoflavone) from the seed germs [6]. The seed extracts of $C$. cajan exhibit hypolipidemic, antioxidant, and antimicrobial activities [7,8]. The seed coat of leguminous plant constitutes major by-product of milling industries. It is utilized mainly as cattle feed and also in manufacture of biscuits [9], and cotyledon used as "dal" in our daily diet. The seed coat has been proved to be an excellent material for treating wastewaters containing low concentration of metal ions [10]. Seed coats act as a potential great resource for the development of antioxidant and antihyperglycemic nutraceuticals. [11]. Antibacterial activity has already been reported in leaf, seed, root, pod, and flower extracts of $C$. cajan [12-14]. Literature survey revealed that the seed coat and cotyledon extracts have yet not been screened for its traditional claim of antibacterial activity and little attention was paid on medicinal properties of seed coat and cotyledon. Hence, the present work was carried out to explore the antibacterial properties of seed coat and cotyledon of $C$. cajan

\section{METHODS}

Plant material collection

The seeds of $C$. cajan var. Maruti (ICP-8863) belonging to the family Fabaceae were collected from Agriculture Research Station, Kalaburgi, Karnataka state, India. The variety Maruti ICP-8863 (PN-ABR-333) was authenticated by plant material description no. 44, International Crops Research Institute for the Semi-Arid Tropics, Patancheru, Andhra Pradesh, India [15]

\section{Processing of sample}

The seeds were moistened for $1 \mathrm{~h}$ and then dried in oven at $55^{\circ} \mathrm{C}$ overnight. The hull or seed coat was removed mechanically using hand grinder. The two fractions such as seed coat and cotyledon were made into fine powder using grinder.

\section{Preparation of extract}

$500 \mathrm{~g}$ of the powdered seed coat and cotyledon were successively extracted by the Soxhlet extractor method $\left(60-80^{\circ} \mathrm{C}\right)$ using $2.5 \mathrm{~L}$ of petroleum ether (PE), chloroform $\left(\mathrm{CHCl}_{3}\right)$, ethanol (Et-OH 95\%, v/v), and water (Aq) solvents in the increasing order of polarity for $18 \mathrm{~h}$. The extracts obtained were dried at $40^{\circ} \mathrm{C}$.

\section{Phytochemical screening}

The seed coat and cotyledon extracts were screened for alkaloids, flavonoids, glycosides, saponins, tannins, phenols, lignins, and steroids as described by Harborne [16]. 


\section{Test microorganisms}

The bacterial strains used in the present study are Bacillus subtilis, Staphylococcus aureus, and Streptococcus pneumoniae a Gram-positive and Salmonella typhi, Klebsiella pneumoniae, Escherichia coli, and Pseudomonas aeruginosa a Gram-negative organism, which were obtained from the Department of Microbiology, Gulbarga University, Kalaburgi, Karnataka, India. They were maintained at $4^{\circ} \mathrm{C}$ on the slants of nutrient agar medium for further use.

\section{Reconstitution of the extracts}

$1 \mathrm{~g}$ of petroleum ether, chloroform, and ethanol and aqueous extracts were reconstituted with $2 \mathrm{~mL}$ of dimethyl sulfoxide to obtain a concentration of 50 and $100 \mathrm{mg} / \mathrm{mL}$ of each extract.

\section{Screening of antibacterial activity}

The agar well-diffusion method was used to determine the inhibitory effects of the extracts against the microbes [17]. The bacterial isolates obtained were first grown in nutrient broth for $18 \mathrm{~h}$ at $37^{\circ} \mathrm{C}$. Simultaneously, Mueller-Hinton Agar medium was prepared and $18 \mathrm{~mL}$ of medium was poured into sterile Petri dishes while hot and then they are allowed to set till solidified. After this stipulated period, $0.2 \mathrm{~mL}$ of the broth culture of the bacteria was aseptically inoculated on this plate using a sterile cotton swab and allowed to dry. A standard sterile cork borer of $8 \mathrm{~mm}$ diameter was used to cut four uniform wells on the surface of the agar. Four wells on each isolate plate were filled with each of the crude extracts with the aid of a sterile syringe. In the similar way, one agar plates for each microorganism were prepared for studying the activity of standard streptomycin $(0.4 \mathrm{mg} / \mathrm{mL})$. The plates were incubated at $37^{\circ} \mathrm{C}$ for $18-24 \mathrm{~h}$ and observed for zones of inhibition. A zone of clearance around each well signifies the inhibition, and the diameter of such zones was measured in millimeter (mm) with a transparent ruler [18].

\section{Statistical analysis}

The data of all measurements are means from three replications. Data and statistical significance of difference were evaluated with analysis of variance using SPSS 10.0 package.

\section{RESULTS}

\section{Phytochemicals}

The phytochemicals detected in C. cajan seed coat and cotyledon extracts are listed in Table 1. Test for flavonoids, tannins, phenols, glycosides, alkaloids, steroids, and lignins were positive in all extracts. However, alkaloids and steroids are not detected in the PE and chloroform extracts of seed coat and cotyledon, whereas the saponins was absent in all extracts of seed coat and cotyledon.

\section{Antibacterial activity}

Antibacterial activity of different solvent extracts of seed coat of C. cajan was assayed against various Gram-positive and Gram-negative bacterial pathogens by agar well-diffusion method as shown in Table 2 . The ethanolic extracts of seed coat showed the highest activity on both Gram-positive and Gram-negative bacteria when compared with the aqueous, chloroform, and PE extracts, except $S$. pneumoniae and $P$. aeruginosa. However, the PE and chloroform extract were resistant to $S$. aureus, and PE extract was resistant to $S$. typhi. The ethanolic extract of seed coat was more sensitive against B. subtilis $(22.0 \pm 0.13 \mathrm{~mm})$ followed by $S$. aureus $(18.0 \pm 0.02 \mathrm{~mm}), K$. pneumoniae $(18.0 \pm 0.09 \mathrm{~mm})$, S. typhi $(15.0 \pm 0.08 \mathrm{~mm})$, and E. coli $(14.5 \pm 0.06 \mathrm{~mm})$ at $100 \mathrm{mg} / \mathrm{mL}$, respectively.

Different solvent extracts of cotyledon showed significant antibacterial activity against $B$. subtilis, $S$. aureus, and $S$. typhi. Whereas, S. pneumoniae, K. pneumoniae, E. coli, and P. aeruginosa were totally resistant to all tested extracts of cotyledon (Table 3). The aqueous cotyledon extract was the most effective against the $S$. aureus and $S$. typhi at $100 \mathrm{mg} / \mathrm{mL}$. The B. subtilis shows maximum inhibition zone in ethanol extract $(15 \pm 0.12 \mathrm{~mm})$ followed by PE extract $(10.0 \pm 0.02 \mathrm{~mm})$ at $100 \mathrm{mg} / \mathrm{mL}$. The chloroform and aqueous extracts were resistant to $B$. subtilis. Similarly, $S$. aureus showed maximum inhibition zone in the aqueous extract $(21.0 \pm 0.02 \mathrm{~mm})$ followed by ethanol $(16.0 \pm 0.04 \mathrm{~mm})$ and PE $(13.0 \pm 0.01 \mathrm{~mm})$ at $100 \mathrm{mg} / \mathrm{mL}$. Chloroform extract was resistant to $S$. aureus. The $S$. typhi showed maximum inhibition zone in the aqueous extract $(20.0 \pm 0.04 \mathrm{~mm})$ than for the ethanol extract $(15.0 \pm 0.03 \mathrm{~mm})$ at $100 \mathrm{mg} / \mathrm{mL}$, the PE and chloroform extracts were resistant to $S$. typhi.

\section{DISCUSSION}

The plant extracts proved promising natural antimicrobial agents with potential applications in infectious disease for controlling pathogenic bacteria. The phytochemical tests revealed the presence of flavonoids, tannins, phenols, glycosides, alkaloids, steroids, and lignins in seed coat and cotyledon of $C$. cajan. Biologically, important specific compounds have been identified in leaf extracts of the $C$. cajan $[19,20]$. The demand for more natural antimicrobial has driven scientists to examine the effectiveness of inhibitory compounds such as extracts from plants [21]. Secondary metabolites such as tannins, steroid, alkaloids, flavonoids, and glycosides have the antimicrobial properties [22,23]. The presence of these metabolites may support the antibacterial activity of seed coat and cotyledon extracts of $C$. cajan.

The present results show that seed coat extract was more sensitive against Gram-positive and Gram-negative bacteria compared to cotyledon extracts. The method of extraction and the microorganism to be targeted would be important factors to consider for optimal activity of the extract. The growth inhibitory effect usually depends on concentration [24]. This is important to identify the dosage and rate at which the extract inhibits the growth of organism [25]. The study revealed that higher concentration at $100 \mathrm{mg} / \mathrm{ml}$ of ethanolic extract of seed coat shows maximum activity against $B$. subtilis and aqueous extract of cotyledon was more sensitive against $S$. aureus and $S$. typhi. The difference in the observed activities of the various extracts may be due to varying degrees of solubility of the active constituents in the solvents used. It has been documented that different solvents have diverse solubility capacities for different phytoconstituents [26]. Doppalapudi has reported the better action

Table 1: Preliminary phytochemical screening of seed coat and cotyledon of $C$. cajan L.

\begin{tabular}{|c|c|c|c|c|c|c|c|c|}
\hline \multirow[t]{2}{*}{ Secondary metabolites } & \multicolumn{4}{|c|}{ Seed coat } & \multicolumn{4}{|c|}{ Cotyledon } \\
\hline & PE & $\mathrm{CHCl}_{3}$ & Et-OH & Aq & PE & $\mathrm{CHCl}_{3}$ & Et-OH & Aq \\
\hline Phenols & + & + & + & + & + & + & + & + \\
\hline Flavonoids & + & + & + & + & + & + & + & + \\
\hline Lignins & + & + & + & + & + & + & + & + \\
\hline Sterols & - & - & + & + & - & - & + & + \\
\hline Alkaloids & - & - & + & + & - & - & + & + \\
\hline Glycosides & + & + & + & + & + & + & + & + \\
\hline Saponins & - & - & - & - & - & - & - & - \\
\hline
\end{tabular}

+: Present, -: Absent, PE: Petroleum ether, $\mathrm{CHCl}_{3}$ : Chloroform, Et-OH: Ethanol, Aq: Aqueous extracts. C. cajan: Cajanus cajan 
Table 2: Antibacterial activity of seed coat extracts of $C$. cajan

\begin{tabular}{|c|c|c|c|c|c|c|}
\hline \multirow{2}{*}{$\begin{array}{l}\text { Extracts } \\
\text { microorganisms }\end{array}$} & \multicolumn{6}{|l|}{ Zone of inhibition in $\mathrm{mm}$} \\
\hline & Concentration $\mathrm{mg} / \mathrm{mL}$ & PE & Chloroform & Ethanol & Aqueous & Streptomycin $0.4 \mathrm{mg} / \mathrm{mL}$ \\
\hline Gram-positive bacteria & 50 & $12.0 \pm 0.2$ & $13.0 \pm 0.05$ & $16.0 \pm 0.05$ & $12.0 \pm 0.05$ & $25.0 \pm 0.1$ \\
\hline B. subtilis & 100 & $13.0 \pm 0.4$ & $13.5 \pm 0.15$ & $22.0 \pm 0.13$ & $12.0 \pm 0.02$ & \\
\hline \multirow[t]{2}{*}{ S. aureus } & 50 & - & - & $13.0 \pm 0.04$ & $14.0 \pm 0.07$ & $28.0 \pm 0.0$ \\
\hline & 100 & - & - & $18.0 \pm 0.02$ & $15.0 \pm 0.03$ & \\
\hline \multirow[t]{2}{*}{ S. pneumoniae } & 50 & - & - & - & - & $19.0 \pm 0.5$ \\
\hline & 100 & - & - & - & - & \\
\hline Gram-negative bacteria & 50 & - & $12.0 \pm 0.05$ & $10.0 \pm 0.05$ & $14.0 \pm 0.04$ & $21.0 \pm 0.2$ \\
\hline S. typhi & 100 & - & $13.0 \pm 0.02$ & $15.0 \pm 0.08$ & $12.0 \pm 0.5$ & \\
\hline \multirow[t]{2}{*}{ K. pneumoniae } & 50 & $11.0 \pm 0.02$ & $12.5 \pm 0.06$ & $13.0 \pm 0.2$ & $12.0 \pm 0.12$ & $22.0 \pm 0.5$ \\
\hline & 100 & $13.0 \pm 0.05$ & $14.0 \pm 0.04$ & $18.0 \pm 0.09$ & $13.0 \pm 0.05$ & \\
\hline \multirow[t]{2}{*}{ E. coli } & 50 & $11.0 \pm 0.04$ & $12.0 \pm 0.02$ & $14.0 \pm 0.04$ & $13.0 \pm 0.02$ & $15.0 \pm 0.5$ \\
\hline & 100 & $13.0 \pm 0.05$ & $14.0 \pm 0.04$ & $14.5 \pm 0.06$ & $14.0 \pm 0.04$ & \\
\hline \multirow[t]{2}{*}{ P. aeruginosa } & 50 & - & - & - & - & $27.0 \pm 0.2$ \\
\hline & 100 & - & - & - & - & \\
\hline
\end{tabular}

Each value is expressed as mean \pm SD. $(\mathrm{n}=3)$ and statistically significant at $\mathrm{P}<0.05$. B. subtilis: Bacillus subtilis, S. aureus: Staphylococcus aureus,

S. pneumoniae: Streptococcus pneumoniae, S. typhi: Salmonella typhi, K. pneumoniae: Klebsiella pneumoniae, E. coli: Escherichia coli, P. aeruginosa: Pseudomonas

aeruginosa

Table 3: Antibacterial activity of cotyledon extracts of $C$. cajan

\begin{tabular}{|c|c|c|c|c|c|c|}
\hline \multirow{2}{*}{$\begin{array}{l}\text { Extracts } \\
\text { microorganisms }\end{array}$} & \multicolumn{6}{|l|}{ Zone of inhibition in $\mathrm{mm}$} \\
\hline & Concentration mg/mL & PE & Chloroform & Ethanol & Aqueous & Streptomycin $0.4 \mathrm{mg} / \mathrm{mL}$ \\
\hline Gram-positive bacteria & 50 & $09.0 \pm 0.13$ & - & $12.0 \pm 0.01$ & - & $25.0 \pm 0.1$ \\
\hline B. subtilis & 100 & $10.0 \pm 0.02$ & - & $15 \pm 0.12$ & - & \\
\hline \multirow{2}{*}{ S. aureus } & 50 & $12.0 \pm 0.05$ & - & $13.0 \pm 0.04$ & $15.0 \pm 0.05$ & $28.0 \pm 0.0$ \\
\hline & 100 & $13.0 \pm 0.01$ & - & $16.0 \pm 0.04$ & $21.0 \pm 0.02$ & \\
\hline \multirow[t]{2}{*}{ S. pneumoniae } & 50 & - & - & - & - & $19.0 \pm 0.5$ \\
\hline & 100 & - & - & - & - & \\
\hline Gram-negative bacteria & 50 & - & - & $12.0 \pm 0.07$ & $15.0 \pm 0.02$ & $21.0 \pm 0.2$ \\
\hline S. typhi & 100 & - & - & $15.0 \pm 0.03$ & $20.0 \pm 0.04$ & \\
\hline \multirow{2}{*}{ K. pneumoniae } & 50 & - & - & - & - & $22.0 \pm 0.5$ \\
\hline & 100 & - & - & - & - & \\
\hline \multirow[t]{2}{*}{ E. coli } & 50 & - & - & - & - & 15. $0 \pm 0.5$ \\
\hline & 100 & - & - & - & - & \\
\hline \multirow{2}{*}{ P. aeruginosa } & 50 & - & - & - & - & $27.0 \pm 0.2$ \\
\hline & 100 & - & - & - & - & \\
\hline
\end{tabular}

Each value is expressed as mean \pm SD. $(\mathrm{n}=3)$ and statistically significant $\mathrm{P}<0.05$. B. subtilis: Bacillus subtilis, S. aureus: Staphylococcus aureus, S. pneumoniae: Streptococcus pneumoniae, S. typhi: Salmonella typhi, K. pneumoniae: Klebsiella pneumoniae, E. coli: Escherichia coli, P. aeruginosa: Pseudomonas aeruginosa

of aqueous and ethanolic extracts of seeds of Vigna unguiculata against B. subtilis and E. coli [27]. There are reports on the ethanolic and aqueous extracts of $C$. cajan leaves, and seeds were effective in producing inhibition zones against $S$. aureus, E. coli, and P. aeruginosa [14]. Similarly, Banala et al. have reported the ethanolic and methanolic extract of leaf, root, pod, and flower extracts of C. cajan against $S$. aureus and E. coli [12].

\section{CONCLUSION}

This study shows that ethanolic and aqueous extract of seed coat and cotyledon of $C$. cajan had potential antibacterial activity against Gram-positive and Gram-negative bacteria, and these extracts may be exploited for the development of anti-microbial and alternative remedies for infections and diseases caused by respective pathogens. Further studies are needed to isolate and characterize the bioactive principles to develop new antimicrobial drugs.

\section{ACKNOWLEDGMENT}

The authors are thankful to the Chairman, Department of Botany, Gulbarga University, Gulbarga, and the Principal, Karnatak College, Bidar, for providing the laboratory facilities.

\section{CONFLICT OF INTEREST STATEMENT}

There is no conflict of interest

\section{REFERENCES}

1. Edeoga HO, Okue DE, Mbaebie BO. Phytochemical constituents of some Nigerian medicinal plants. Afr J Biotechnol 2005;4:685-8.

2. Soberón JR, Sgariglia MA, Sampietro DA, Quiroga EN, Vattuone MA. Antibacterial activity of plant extracts from northwestern argentina. J Appl Microbiol 2007;102:1450-61.

3. van der Watt E, Pretorius JC. Purification and identification of active antibacterial components in carpobrotus edulis L. J Ethnopharmacol 2001;76:87-91.

4. Sharif MD, Banik GR. Status and utilization of medicinal plants in Rangamati of Bangladesh. Res J Agric Biol Sci 2006;2:268-73.

5. Saxena KB, Vijaya KR, Sultana R. Quality nutrition through pigeon pea: A review. Health 2010;2:1335-44.

6. CSIR (Council of Scientific and Industrial Research). Wealth of India. Raw Materials. Vol. 3. New Delhi: CSIR; 1999.

7. Oboh G. Antioxidant properties of some commonly consumed and underutilized tropical legumes. Eur Food Res Technol 2006;224:61-5.

8. Kanatt SR, Arjun K, Sharma A. Antioxidant and antimicrobial activity of legume hulls. Food Res Int 2011;44:3182-7.

9. Tiwari BK, Brennan CS, Jaganmohan R, Surabi A, Alagusundaram K. 
Utilisation of pigeon pea (Cajanus cajan L.) by products in biscuit manufacture. Food Sci Technol Int 2011;44:1533-7.

10. Ahalya N, Kanamadi RD, Ramachandra TV. Cr (VI) and Fe (III) removal using Cajanus cajan husk. J Environ Biol 2007;28:765-9.

11. Kumar TA, Abhinay B, Babu KS, Kumar DA, Zehra A, Madhusudana K. Pigeon pea seed husks as potent natural resource of anti-oxidant and anti-hypoglycemic activity. Int J Green Pharm 2015;7:252-7.

12. Banala M, Srikanth K, Archana P, Chamundeshwari E, Nanna R. In vitro antibacterial activity of leaf, seed, root, pod and flower extracts of Cajanus cajan (L.) Millsp. Int J Pharm Pharm Sci 2015;7:265-8.

13. Nwachukwu E, Uzoeto HO. Antimicrobial activities of leaf of Vitex doniana and Cajanxus cajan on some Bacteria. Researcher 2010;2:38-47.

14. Ezeifeka GO, Orji MU, Mbata TI, Patrick AO. Antimicrobial activities of Cajanus cajan, Garcinia kola and Xylopia aethiopica on pathogenic microorganisms. Biotechnology 2004;3:41-3.

15. ICRISAT. Plant Material Description No. 44. Patancheru, Andhra Pradesh: International Crops Research Institute for the SemiArid Tropics; 1993.

16. Harborne JB. Phytochemical Methods, a Guide to Modern Techniques of Plant Analysis. $3^{\text {rd }}$ ed. Madras: Chapman and Hall; 1998.

17. Controller of Publications. Indian Pharmacopoeia. Government of India, Ministry of Health and Family Welfare. Delhi: Controller of
Publications; 1996.

18. Abah SE, Egwari LO. Methods of antimicrobial susceptibility testing of plant extract. Afr J Basic Appl Sci 2011;3:205-20.

19. Dahanukar SA, Kulkarni RA, Rege NN. Pharmacology of medicinal plants and natural products. Indian J Pharmacol 2000;32:S81-118.

20. Cowan MM. Plant products as antimicrobial agents. Clin Microbiol Rev 1999;12:564-82.

21. Nasar-Abbas SM, Halkman AK. Antimicrobial effect of water extract of sumac (Rhus coriaria L.) on the growth of some food born bacteria including pathogens. Int J Food Microbiol 2004;97:63-9.

22. Duke JA. Handbook of Legumes of World Economic Importance. New York: Plenum Press; 1981.

23. Wei ZF, Luo M, Zhao CJ, Li CY, Gu CB, Wang W. UV-induced changes of active components and antioxidant activity in post-harvest pigeon pea (Cajanus cajan L.) leaves. J Agric Food Chem 2013;61:1165-71.

24. Achi OK. Composition and antibacterial activities of Tetrapleura tetraptera Taub. pod extracts. Res J Microbiol 2006;5:416-22.

25. Egwari LO. Antibacterial activity of crude extracts of Nauclea latifolia and Eugenia aromatica. West Afr J Pharmacol Drug Resist 1999; $15: 55-9$

26. Majorie MC. Plant products as antimicrobial agents. Clin Microbiol Rev 1999;12:564-82.

27. Sandeep D. Evaluation of antibacterial activity of seed extracts of Vigna unguiculata. Int J Pharm Pharm Sci 2014;6:75-7. 